\title{
Recomendaciones para el diagnóstico, manejo y prevención de la influenza en Chile. Período 2013
}

\author{
FERNANDO SALDÍAS P.*
}

\section{Recommendations for diagnosis, management and prevention of influenza in Chile, 2013}

Influenza virus infection causes significant morbidity and mortality in Chile each year. The majority of persons infected with influenza virus exhibit self-limited, uncomplicated, acute febrile respiratory symptoms or are asymptomatic. However, severe disease and complications due to infection, including hospitalization and death, may occur in elderly and very young people, in those with underlying medical conditions (including pulmonary and cardiac disease, diabetes, and immunosuppression), in pregnant women and in previously healthy people. Early treatment with antiviral medications may reduce the severity and duration of symptoms, hospitalizations, and complications (otitis media, bronchitis, pneumonia), and may reduce the use of outpatient services and antibiotics, extent and quantity of viral shedding, and possibly mortality in certain populations. Vaccination is the best method for preventing influenza, but antivirals may also be used as primary or secondary means of preventing influenza transmission in certain settings. We review the main recommendations for the diagnosis, treatment and prevention of influenza in our country.

Key words: Influenza, vaccination, antivirals, neuraminidase inhibitors, diagnosis, treatment, prevention.

\section{Resumen}

La infección por virus influenza ocasiona importante morbilidad y mortalidad en Chile durante el período de otoño-invierno. La mayoría de las personas infectadas con el virus de la gripe presentan sintomas respiratorios agudos y fiebre autolimitados, sin complicaciones, o son asintomáticos. Sin embargo, enfermedad respiratoria grave y complicaciones debido a la infección viral, incluida la hospitalización y la muerte, pueden ocurrir en personas de edad avanzada, en niños menores de dos años, personas con condiciones médicas subyacentes (incluida la enfermedad pulmonar y cardiaca crónica, diabetes e inmunosupresión), embarazadas y en personas previamente sanas. La pesquisa y tratamiento precoz con medicamentos antivirales (inhibidores de la neuraminidasa) puede reducir la gravedad y duración de los síntomas, riesgo de hospitalización y complicaciones (otitis media, bronquitis, neumonía), y puede reducir el uso de los servicios de atención ambulatoria y prescripción de antibióticos, acortar el periodo de transmisibilidad de la infección en la comunidad y, posiblemente, la mortalidad en ciertas poblaciones de riesgo. La vacunación es el método de elección para la prevención de la gripe en la comunidad, pero los medicamentos antivirales también pueden ser utilizados como medio primario o secundario de prevención de la transmisión de la influenza en ciertos contextos epidemiológicos. Se revisan las principales recomendaciones para el diagnóstico, tratamiento y prevención de la influenza en nuestro país.

Palabras clave: Influenza, vacunación, antivirales, inhibidores de neuraminidasas, diagnóstico, tratamiento, prevención.

* Comisión de Infecciones de la Sociedad Chilena de Enfermedades Respiratorias. Departamento de Enfermedades Respiratorias, Pontificia Universidad Católica de Chile. 


\section{Introducción}

Las enfermedades respiratorias ocupan el tercer lugar como causa de muerte en los últimos diez años en Chile, luego de las enfermedades cardiovasculares y neoplasias ${ }^{1}$. En esta categoría, las principales causas de muerte son las infecciones respiratorias (especialmente Influenza y Neumonía), EPOC y Cáncer pulmonar ${ }^{1}$. La tasa de mortalidad por causas respiratorias fue 58,5 por 100.000 habitantes en el año 2010, sin diferencias significativas por género. La mortalidad por infecciones respiratorias en nuestro país ha declinado en las últimas dos décadas desde cifras cercanas a 50 por 100.000 habitantes hasta cifras cercanas a 20 por 100.000 habitantes, ocasionando cerca de 4.000 muertes en el año 2010.

La influenza es una enfermedad respiratoria infectocontagiosa provocada por los virus de la influenza A y B, que puede ocasionar cuadros leves que requerirán tratamiento sintomático ambulatorio hasta cuadros graves con falla respiratoria aguda progresiva que pueden llevar a la muerte ${ }^{2-4}$. El período de incubación puede variar entre 1 y 4 días desde el contacto ${ }^{5}$. Se manifiesta por síntomas inespecíficos, comunes a otras infecciones respiratorias virales del período otoño-invierno, asociado a fiebre de inicio brusco $\left(38-40^{\circ} \mathrm{C}\right)$ que dura entre 1 y 5 días, malestar general, mialgias, cefalea, tos y síntomas respiratorios altos o síntomas digestivos ${ }^{3,4}$.

Ambos virus pueden ocasionar epidemias estacionales de influenza durante los meses de otoñoinvierno y casos esporádicos o brotes fuera de temporada ${ }^{2}$. Durante la temporada de influenza, los virus circulan ampliamente en la población, con una tasa de ataque anual estimada de 5-10\% en adultos y $20-30 \%$ en los niños. En climas templados, las epidemias estacionales acontecen sobre todo durante el invierno; mientras que en las regiones tropicales, casos de influenza pueden presentarse durante todo el año, causando brotes más irregulares.

La principal forma de trasmisión de la enfermedad es el contagio de persona a persona, a través de gotitas que quedan suspendidas en el aire después de que un paciente con influenza tose o estornuda ${ }^{2}$. También es posible adquirir la infección cuando se tocan objetos contaminados con gotitas provenientes de un paciente infectado y se llevan a la boca o nariz sin lavarse previamente las manos. De este modo, las principales medidas de prevención de esta condición en la comunidad y ambiente hospitalario son el lavado de manos, aislamiento respiratorio del caso índice, recambio frecuente del aire de sitios cerrados, evitar el hacinamiento, promover formas de vida saludable, prevención del tabaquismo y exposición a ambientes contaminados, manejo óptimo de las enfermedades crónicas y trastornos nutricionales, cubrir la boca y la nariz con el antebrazo en caso de tos o estornudo, pesquisa y tratamiento precoz de los $\operatorname{casos}^{3}$. Junto con esto, la mejor manera de evitar contraer esta enfermedad y en especial las complicaciones graves, es la vacunación de la población de riesgo ${ }^{6,7}$.

Aunque la mayoría de los enfermos desarrollan un cuadro respiratorio febril autolimitado de manejo ambulatorio, se han identificado grupos de riesgo que tienen mayor probabilidad de sufrir complicaciones graves, a quienes están dirigidas las medidas de prevención: niños menores de cinco años, adultos mayores de 65 años, inmunodeprimidos (infección por VIH, cáncer, quimioterapia, tratamiento inmunosupresor), portadores de enfermedades crónicas (asma, EPOC, fibrosis quística, daño pulmonar crónico, diabetes mellitus, cardiopatías, insuficiencia cardíaca congestiva, insuficiencia renal crónica, enfermedad neuromuscular, epilepsia o déficit cognitivo, enfermedad hepática crónica), embarazadas, pacientes institucionalizados (Tablas 1 y 2$)^{2-4}$.

El programa de inmunización contra la influenza disminuye las complicaciones graves y mortalidad asociada a esta condición, está dirigido a subgrupos de la población definidos por

Tabla 1. Factores de riesgo de complicaciones 0 enfermedad respiratoria aguda grave en pacientes adultos con influenza

Adultos mayores de 65 años

Enfermedad cardiovascular-Insuficiencia cardíaca congestiva

Enfermedades respiratorias crónicas (asma, fibrosis quística, enfermedad pulmonar obstructiva crónica)

Enfermedad neurológica crónica (enfermedad neuromuscular, epilepsia, deterioro cognitivo)

Enfermedades metabólicas-Diabetes mellitus

Inmunodepresión (infección por VIH, inmunodeficiencias primarias y secundarias)

Neoplasias

Anemia de células falciformes y otras hemoglobinopatías

Embarazo

Obesidad mórbida (IMC $>40 \mathrm{~kg} / \mathrm{m}^{2}$ )

Insuficiencia renal crónica

Daño hepático crónico

Pacientes institucionalizados 
Tabla 2. Factores de riesgo de complicaciones o enfermedad respiratoria aguda grave en pacientes pediátricos con influenza

Edad: menor de 2 años
Cardiopatías congénitas
Asma bronquial
Síndrome bronquial obstructivo recidivante
Daño pulmonar crónico-Fibrosis quística
Diabetes mellitus
Enfermedad neuromuscular
Epilepsia
Insuficiencia renal crónica
Inmunodepresión (infección por VIH, inmunodeficien-
cias primarias y secundarias)
Pacientes institucionalizados

condiciones biomédicas que se asocian a mayor riesgo de muerte y complicaciones asociadas a la infección por el virus influenza ${ }^{3,6,7}$. El programa de vacunación anti-influenza del año 2013 se ajustará a las recomendaciones de la Organización Mundial de la Salud para el hemisferio sur: La vacuna trivalente estará compuesta de los virus $\mathrm{A} /$ California/7/2009 $\left(\mathrm{H}_{1} \mathrm{~N}_{1}\right)$, A/Victo$\mathrm{ria} / 361 / 2011\left(\mathrm{H}_{3} \mathrm{~N}_{2}\right)$ y B/Wisconsin/1/2010.

En el brote epidémico de influenza del año 2009 , las infecciones respiratorias agudas graves se observaron principalmente en los grupos de edades extremas de la vida: menores de cinco años y adultos mayores ${ }^{8,9}$. La tasa de hospitalización fue seis veces mayor en el adulto mayor de 60 años comparado con la población general, seguido por los niños menores de 5 años con una tasa tres veces mayor que la general ${ }^{8-11}$. Se identificó además como factor de riesgo la presencia de comorbilidad (especialmente en el adulto joven), obesidad mórbida y el embarazo.

La Organización Mundial de la Salud ha señalado que después de la epidemia de infección por virus influenza $\mathrm{A}\left(\mathrm{H}_{1} \mathrm{~N}_{1}\right)$ del año 2009 , el mundo se encuentra en el período post-pandémico ${ }^{12}$. Se espera que el virus de la influenza $\mathrm{A}\left(\mathrm{H}_{1} \mathrm{~N}_{1}\right)$ 2009 se comporte, en adelante, como un virus estacional, que continuará circulando en los próximos años. Ante este escenario, y el riesgo constante de circulación de nuevos virus con alto riesgo pandémico, la OPS/OMS reitera que siguen vigentes las recomendaciones formuladas en el Protocolo Genérico para la Vigilancia de la Influenza OPS-CDC, se recomienda mantener la alerta y prepararse para mitigar el impacto de una eventual nueva pandemia ${ }^{12,13}$.
El programa de inmunización de la población de riesgo, la adecuada organización de los recursos humanos y materiales de los prestadores de salud y la vigilancia epidemiológica de la Enfermedad Tipo Influenza (ETI) constituyen las estrategias centrales del enfrentamiento de la Influenza en el período epidémico de otoñoinvierno ${ }^{6,7,12-14}$. Esta actividad de pesquisa de casos se realiza mediante establecimientos centinela ambulatorios para la vigilancia de la Enfermedad Tipo Influenza (ETI) y en hospitales para la circulación de los virus respiratorios; el monitoreo de las consultas de urgencia por síndromes respiratorios, de las hospitalizaciones por infección respiratoria aguda grave y de las defunciones de causa respiratoria ${ }^{1,14}$

\section{Diagnóstico}

El diagnóstico presuntivo de influenza se establece en toda persona que consulta por cuadro respiratorio de evolución aguda con fiebre mayor o igual a $38,5{ }^{\circ} \mathrm{C}$ axilar y tos, asociado a uno o más de los siguientes síntomas: cefalea, mialgias, odinofagia; y contacto con caso sospechoso o confirmado de influenza durante el período epidémico ${ }^{12-14}$. En pacientes adultos, la aparición brusca de fiebre y tos durante la temporada de influenza permite establecer el diagnóstico de gripe en el ámbito ambulatorio con una sensibilidad superior al $70 \%{ }^{15-17}$. La influenza está asociada a una gran variedad de signos y síntomas que pueden variar con la edad, comorbilidad, complicaciones y estado inmune del huésped. Los niños pequeños se pueden presentar con fiebre y sospecha de sepsis ${ }^{18}$. La diarrea se puede presentar en hasta el $28 \%$ de los lactantes y niños pequeños infectados, aunque los síntomas respiratorios altos y manifestaciones sistémicas constituyen la presentación más común ${ }^{19}$. En la población senescente puede no haber fiebre y la exacerbación de las enfermedades crónicas es común (por ejemplo, enfermedad pulmonar obstructiva crónica, asma e insuficiencia cardiaca congestiva) $)^{20-24}$.

El uso apropiado de las pruebas de diagnóstico, junto con la administración oportuna de medicamentos antivirales, puede mejorar los resultados clínicos de la infección por virus influenza, puede reducir las pruebas diagnósticas innecesarias, la duración de la atención médica requerida, y el uso inapropiado de antibióticos (por presuntas complicaciones bacterianas). En las guías clínicas, se recomienda el empleo de pruebas de diagnóstico para la pesquisa de casos de influenza, incluyendo técnicas de biología molecular como la reacción en cadena de la polimerasa con transcriptasa 
Tabla 3. Métodos de pesquisa y diagnóstico de influenza en población infantil y adulta

\begin{tabular}{|c|c|c|}
\hline Técnicas & $\begin{array}{l}\text { Tiempo de } \\
\text { respuesta }\end{array}$ & Recomendación \\
\hline $\begin{array}{l}\boldsymbol{R} \boldsymbol{T}-\boldsymbol{P C R} \text { (convencional, en tiempo real } \\
\text { y múltiple) }\end{array}$ & $2 \mathrm{~h}$ & $\begin{array}{l}\text { Sensibilidad y especificidad elevadas } \\
\text { Método diagnóstico de elección }\end{array}$ \\
\hline $\begin{array}{l}\text { Inmunofluorescencia } \\
\text { - Directa } \\
\text { - Indirecta }\end{array}$ & $\begin{array}{l}2-4 h \\
2-4 h\end{array}$ & $\begin{array}{l}\text { Sensibilidad moderada y alta especificidad } \\
\text { Métodos diagnósticos recomendados } \\
\text { Detecta y diferencia virus influenza A y B } \\
\text { Detecta y diferencia virus influenza A y B }\end{array}$ \\
\hline $\begin{array}{l}\text { Test rápidos de influenza } \\
\text { - Detección de antígenos (EIA) } \\
\text { - Detección de neuraminidasa }\end{array}$ & 10-20 min & $\begin{array}{l}\text { Sensibilidad baja-moderada y alta especificidad } \\
\text { La interpretación de los resultados debe considerar las } \\
\text { limitaciones de los diferentes ensayos } \\
\text { Según las características del ensayo puede detectar y/o } \\
\text { diferenciar los virus influenza A y B } \\
\text { Detecta pero no distingue entre virus influenza A y B }\end{array}$ \\
\hline $\begin{array}{l}\text { Cultivo viral } \\
\quad \text { - Shell vial } \\
\text { - Cultivo celular }\end{array}$ & $\begin{array}{l}48-72 \mathrm{~h} \\
3-10 \text { días }\end{array}$ & $\begin{array}{l}\text { Sensibilidad moderada y especificidad muy elevada } \\
\text { Útil como herramienta de vigilancia epidemiológica }\end{array}$ \\
\hline $\begin{array}{l}\text { Pruebas serológicas (ELISA, fijación } \\
\text { de complemento, inhibición de hema- } \\
\text { glutinina y neutralización) }\end{array}$ & & $\begin{array}{l}\text { Sólo disponibles en laboratorios de referencia } \\
\text { Se utiliza en estudios de vigilancia epidemiológica o en } \\
\text { estudios de investigación }\end{array}$ \\
\hline
\end{tabular}

inversa (RT-PCR), los ensayos de inmunofluorescencia, las pruebas rápidas disponibles comercialmente para diagnóstico de influenza y el cultivo viral en células de tejido ${ }^{3,12,13}$. En la Tabla 3 se describen los principales exámenes empleados en el diagnóstico de influenza.

En los pacientes que se hospitalizan por infección respiratoria aguda grave o neumonía sin causa etiológica conocida durante el período epidémico, se recomienda solicitar estudio microbiológico dirigido para confirmar o descartar la infección por virus Influenza ${ }^{3}$. La confirmación diagnóstica se efectúa mediante la detección de antígenos en muestras respiratorias (hisopado nasofaríngeo, aspirado nasal o faríngeo) por técnica de inmunofluorescencia directa, teniendo en consideración que el examen positivo permite confirmar el diagnóstico (elevada especificidad) pero el examen negativo no permite descartar el diagnóstico (sensibilidad moderada) especialmente en períodos de alta circulación del virus ${ }^{25}$. En caso de duda diagnóstica, se recomienda solicitar el examen de RT-PCR o cultivo viral de muestras respiratorias para confirmar o descartar el diagnóstico en la población de riesgo, de acuerdo a la disponibilidad local.

En los pacientes pediátricos y adultos con cuadro clínico sugerente de influenza o gripe se recomienda descartar otras causas infecciosas frecuentes durante el invierno, tales como infecciones de la vía aérea superior (faringoamigdalitis, otitis, sinusitis), laringitis, epiglotitis, bronquiolitis, bronquitis o neumonía ${ }^{2-5,15-17}$. El síndrome gripal puede ser ocasionado por otros virus respiratorios, tales como adenovirus, virus parainfluenza, virus sincicial respiratorio, metapneumovirus, enterovirus y hantavirus, entre otros.

\section{Tratamiento}

El manejo ambulatorio de los pacientes con gripe o influenza no complicada se basa en las medidas generales recomendadas a todos los pacientes que lo requieran y el tratamiento específico con medicamentos antivirales (inhibidores de la neuraminidasa y derivados de adamantano) en los pacientes con factores de riesgo de complicaciones o enfermedad respiratoria aguda grave $^{3,12-14}$. A su vez, el tratamiento con fármacos antivirales se recomienda a todo paciente hospitalizado por ETI o influenza confirmada por exámenes de laboratorio.

\section{Cuidados generales para niños y adultos con influenza $a^{3,12,13,26}$}

- Reducir la actividad física y reposo en cama durante el período febril (1-3 días).

- Medidas de aislamiento del caso índice en el domicilio (precaución de gotitas).

- Régimen liviano, hidratación adecuada.

- Lavado frecuente de manos y medidas de higiene general.

- Cubrir la boca y nariz con pañuelo desechable o el antebrazo al toser o estornudar. 
- Uso de antipiréticos para el manejo de la fiebre. Se recomienda no emplear ácido acetilsalićlico en menores de 15 años debido a su asociación con el síndrome de Reye.

- Promover la consulta precoz en caso de deterioro clínico o agravamiento de los síntomas (criterios de gravedad).

\section{Tratamiento antiviral}

Se recomienda prescribir el tratamiento antiviral a aquellos pacientes pediátricos o adultos que presenten alguna condición de riesgo para enfermedad respiratoria aguda grave y cuyo cuadro clínico corresponda a un caso sospechoso o confirmado de influenza (Tabla 4) 3,12,13,27. La administración de los fármacos antivirales antes de 48 horas desde la aparición de los síntomas ha demostrado que logra reducir la duración de los síntomas $^{27-30}$. El efecto es mínimo si su empleo es más tardío, por lo cual se debe enfatizar la pesquisa y tratamiento precoz de los casos. En los sujetos hospitalizados por infección respiratoria aguda grave por influenza o ETI se recomienda iniciar el tratamiento antiviral lo antes posible ${ }^{3,12,13}$.

Los virus de influenza $\mathrm{A}\left(\mathrm{H}_{1} \mathrm{~N}_{1}\right) 2009, \mathrm{~A}\left(\mathrm{H}_{3} \mathrm{~N}_{2}\right)$ e influenza B son susceptibles a los inhibidores de la neuraminidasa (oseltamivir y zanamivir), por lo tanto son los medicamentos de elección para su tratamiento ${ }^{12,13,30}$. Asociado al uso masivo de fármacos antivirales durante la pandemia de 2009 se han detectado casos aislados de resistencia ${ }^{31} ; \sin$ embargo, en Chile aún no se han detectado cepas resistentes a los inhibidores de neuraminidasas. Mientras que los virus influenza A $\left(\mathrm{H}_{1} \mathrm{~N}_{1}\right) 2009$ y A $\left(\mathrm{H}_{3} \mathrm{~N}_{2}\right)$ suelen ser resistentes a amantadina y rimantadina ${ }^{12,13,32}$. Los adamantanos no están indicados para el tratamiento del virus influenza B.

El uso de medicamentos antivirales (inhibidores de la neuraminidasa) en embarazadas de cualquier edad gestacional y mujeres en lactancia con diagnóstico de influenza debe ser indicado considerando que el beneficio sea mayor que el riesgo de la enfermedad (clasificación $\mathrm{C}$ según la FDA $)^{33,34}$. Ambos fármacos no han sido estudiados específicamente en población de mujeres embarazadas. Sin embargo, la categoría C no significa que el medicamento no pueda ser utilizado en esta población. Las gestantes pueden y deben recibir un medicamento de categoría $\mathrm{C}$ cuando los posibles beneficios del uso de la droga son más probables que el posible riesgo de daño para la mujer o su bebé. En las embarazadas hospitalizadas por infección respiratoria aguda grave o compromiso sistémico por influenza, el tratamiento de elección es oseltamivir.

\section{Inhibidores de la neuraminidasa}

Oseltamivir: Es el tratamiento de elección en pacientes con factores de riesgo de complicaciones o enfermedad respiratoria aguda grave. Do-

Tabla 4. Recomendación de medicamentos antivirales en pacientes con influenza y manejo de los contactos

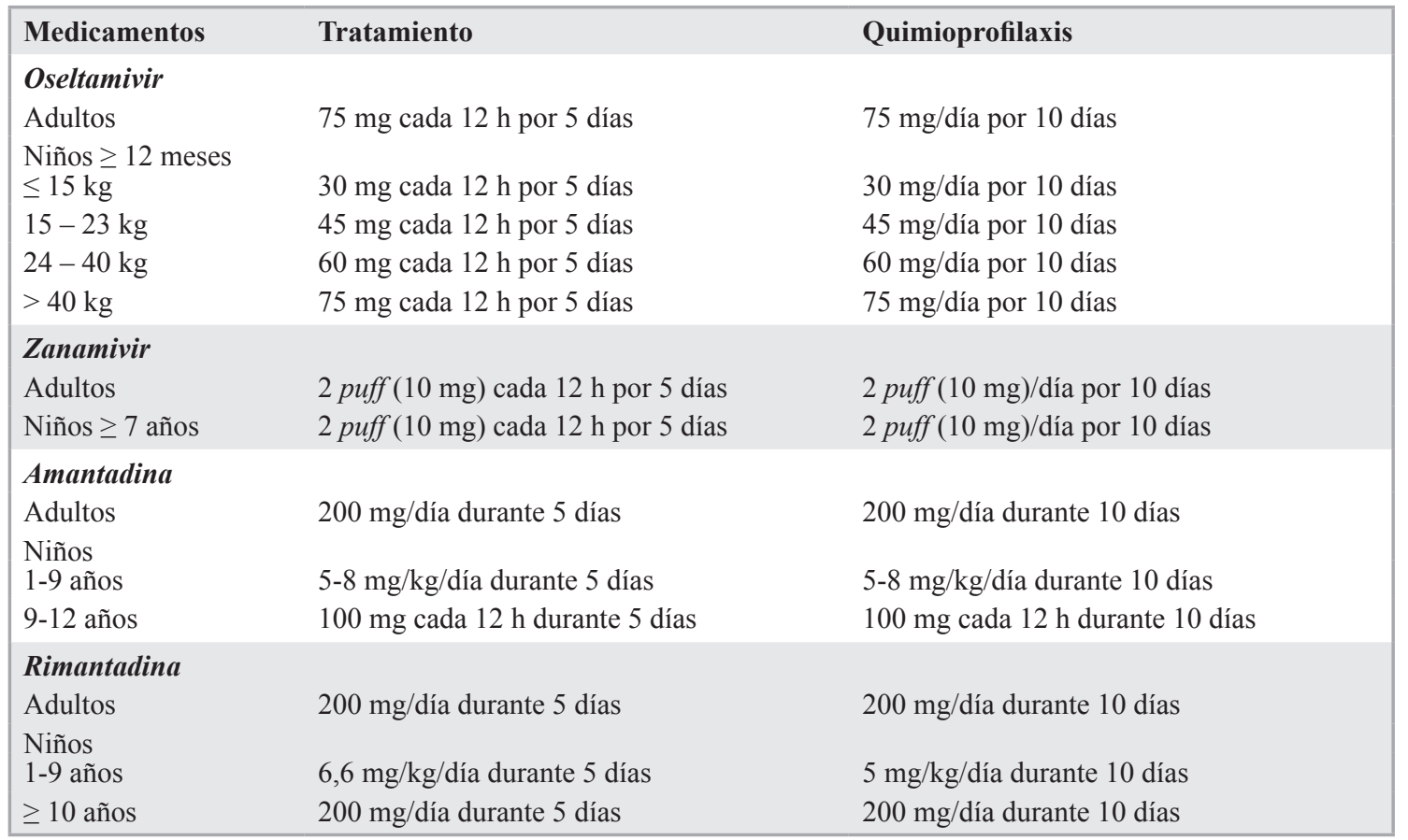


sificación de adultos: $75 \mathrm{mg}$ cada 12 h por 5 días. Se requiere ajustar las dosis en pacientes con insuficiencia renal y en pacientes en hemodiálisis. Contraindicaciones: Reacciones de hipersensibilidad conocida al Oseltamivir. Las reacciones adversas más comunes son nauseas, vómitos, diarrea y dolor abdominal. En las reacciones de hipersensibilidad cutánea graves o aparición de síntomas neuro-psiquiátricos (confusión, alteraciones conductuales) se recomienda suspender el fármaco.

Zanamivir: Es una alternativa para el tratamiento en niños mayores de 7 años y adultos que presentan intolerancia a Oseltamivir. Dosificación: 2 inhalaciones $(10 \mathrm{mg})$ cada $12 \mathrm{~h}$ durante cinco días. Las reacciones adversas más comunes son fiebre, escalofríos, mareos, sinusitis, artralgias y síntomas articulares. Contraindicaciones: Por ser un medicamento inhalatorio, el efecto adverso más relevante sería el broncoespasmo u obstrucción bronquial, por lo tanto no se recomienda su uso en personas con asma, hiperreactividad bronquial o enfermedad pulmonar obstructiva crónica. Con el uso de Zanamivir se han comunicado episodios graves de broncoespasmo, en ocasiones con resultado fatal. En reacciones alérgicas graves y aparición de síntomas neuropsiquiátricos (confusión, convulsiones, alteraciones conductuales) se recomienda suspender el medicamento.

\section{Hospitalización}

Se recomienda hospitalizar a los pacientes adultos que cumplan con la definición de caso sospechoso o confirmado de influenza y presentan alguno de los siguientes criterios de gravedad: Compromiso de conciencia, apremio respiratorio, hipotensión arterial (PAS menor de $90 \mathrm{mmHg}$ ), taquipnea (FR $>24$ ciclos/min), disnea, cianosis, hipoxemia $\left(\mathrm{SpO}_{2}<90 \%\right.$ respirando aire ambiental) y consulta repetida por deterioro clínico.

Se recomienda hospitalizar a los pacientes pediátricos que cumplan con la definición de caso sospechoso o confirmado de influenza y presentan alguno de los siguientes criterios de gravedad: Compromiso hemodinámico, hipoxemia $\left(\mathrm{SpO}_{2}\right.$ $<93 \%$ respirando aire ambiental), deshidratación o rechazo alimentario (en lactantes), dificultad respiratoria o aumento del trabajo respiratorio y consulta repetida por deterioro clínico.

\section{Manejo del paciente hospitalizado con influenza $a^{3,12,13,26}$}

- Se recomienda iniciar el tratamiento antiviral lo antes posible a todo paciente que se hospitalice por influenza.
- Mantener la separación entre los pacientes de al menos un metro en las salas de atención.

- Implementar las medidas de aislamiento de los pacientes en habitación individual o, en caso necesario, en habitación compartida con pacientes con la misma enfermedad.

- Solicitar muestra respiratoria para estudio por inmunofluorescencia, test pack viral, RT-PCR o cultivo viral, según disponibilidad local.

- Cubrir con pañuelos desechables la boca y nariz al toser o estornudar, o como alternativa cubrir la boca y nariz con el antebrazo. En ambos casos realizar lavado de manos posterior.

- Limitar el contacto del paciente hospitalizado con influenza con otras personas (personal de salud, familiares y visitas).

\section{Medidas preventivas instauradas por el personal de salud $d^{3,12,13,26}$}

- Higiene de manos (lavado con agua y jabón o uso de soluciones antisépticas con alcohol) antes y después de atender a un paciente.

- Uso de guantes si se toma contacto con las mucosas o secreciones biológicas.

- Uso de protección facial (mascarilla, antiparras, escudos faciales, etc.), delantal y/o pecheras, especialmente si hay posibilidad de salpicaduras o nebulización de aerosoles.

- En caso de traslado, el paciente deberá utilizar mascarilla de tipo quirúrgico si lo tolera.

- Efectuar limpieza de las superficies de examen entre pacientes o uso de sabanillas desechables en las superficies de examen que se cambiarán entre pacientes. En las superficies contaminadas con materia orgánica (ej.: secreciones respiratorias) se realizará limpieza por arrastre seguida de limpieza con uso de desinfectante en la superficie.

- Se promoverá el manejo adecuado de los equipos, desechos y ropa de los pacientes: Equipos de uso exclusivo del paciente, de no ser así se debe limpiar y desinfectar con alcohol u otro desinfectante. Tratar los desechos como desechos clínicos y lavar la ropa con procedimientos de rutina empleando guantes no estériles.

- Fortalecer las medidas de prevención y control de las infecciones asociadas a los cuidados en salud.

\section{Manejo de los contactos c $^{3,12,13,16}$}

Se define los contactos como aquellas personas que habitan bajo el mismo techo o que han estado en contacto cercano con un paciente con sospecha o confirmación de Influenza. Se incluye al personal de salud en contacto clínico directo con el caso. El contacto cercano se refiere al contacto a 
menos de un metro por un tiempo de exposición mayor a $15 \mathrm{~min}$, con un paciente con sospecha o confirmación diagnóstica de Influenza. Por ejemplo: En la sala de clases, jardín infantil, lugar de trabajo, hospederías, albergues, regimientos, entre otros.

\section{Indicaciones de quimioprofilaxis}

La quimioprofilaxis con fármacos antivirales ha demostrado ser eficaz en la prevención de la influenza en contactos de pacientes con ETI o influenza ${ }^{35-40}$. Se recomienda el uso de quimioprofilaxis en contactos que presenten las condiciones riesgo que se señalan a continuación: a) Embarazada, vacunada o no, que habita bajo el mismo techo o es contacto cercano de un paciente sospechoso o confirmado con influenza; b) Paciente inmunodeprimido o con terapia inmunosupresora, vacunado o no, que habita bajo el mismo techo o es contacto cercano de un paciente sospechoso o confirmado con influenza. El uso de quimioprofilaxis en otros grupos de riesgo (adultos mayores y portadores de enfermedades crónicas) queda a discreción del equipo de salud.

Para limitar la propagación de la infección viral en los centros de salud, sería recomendable el uso de quimioprofilaxis en el personal de salud no vacunado que haya realizado atención clínica directa o administrativa a menos de un metro y por tiempo prolongado a un paciente con influenza confirmada, sin utilizar barrera de protección.

En la quimioprofilaxis se puede utilizar oseltamivir o zanamivir ${ }^{35-40}$. Ambos pueden ser utilizados en embarazadas de cualquier edad gestacional evaluando los beneficios y riesgos del caso. En la Tabla 4 se describen las dosis de los fármacos antivirales empleados en la quimioprofilaxis de influenza y la duración de la terapia.

\section{Bibliografía}

1.- MINISTERIO DE SALUD, CHILE. Departamento de Estadísticas e Información de Salud. http://www.deis. $\mathrm{cl} /$ estadisticas-mortalidad/ Consultado el 4 de marzo de 2013.

2.- COX N J, SUBBARAO K. Influenza. Lancet 1999; 354: 1277-82.

3.- HARPER S A, BRADLEY J S, ENGLUND J A, FILE T M, GRAVENSTEIN S, HAYDEN F G, et al. Seasonal influenza in adults and children-diagnosis, treatment, chemoprophylaxis, and institutional outbreak management: clinical practice guidelines of the Infectious Diseases Society of America. Clin Infect Dis 2009; 48: 1003-32.

4.- PUNPANICH W, CHOTPITAYASUNONDH T. A review on the clinical spectrum and natural history of human influenza. Int J Infect Dis 2012; 16: 714-23.

5.- LESSLER J, REICH N G, BROOKMEYER R, PERL T M, NELSON K E, CUMMINGS D A. Incubation periods of acute respiratory viral infections: a systematic review. Lancet Infect Dis 2009; 9: 291-300.

6.- VACCINES AGAINST INFLUENZA WHO position paper-November 2012. Wkly Epidemiol Rec 2012; 87: 461-76.

7.- CENTERS FOR DISEASE CONTROL AND PREVENTION (CDC). Prevention and control of influenza with vaccines: recommendations of the Advisory Committee on Immunization Practices (ACIP)-United States, 2012-13 influenza season. MMWR Morb Mortal Wkly Rep 2012; 61: 613-8.

8.- BAUTISTA E, CHOTPITAYASUNONDH T, GAO Z, HARPER S A, SHAW M, UYEKI T M, et al. Writing Committee of the WHO Consultation on Clinical Aspects of Pandemic (H1N1) 2009 Influenza. Clinical aspects of pandemic 2009 influenza A (H1N1) virus infection. N Engl J Med 2010; 362: 1708-19.

9.- COWLING B J, CHAN K H, FANG VJ, LAU L L SO $\mathrm{H}$ C, FUNG R O, et al. Comparative epidemiology of pandemic and seasonal influenza $\mathrm{A}$ in households. N Engl J Med 2010; 362: 2175-84.

10.- DABANCH J, PERRET C, NAJERA M, GONZÁLEZ C, GUERRERO A, OLEA A, et al; Advisory Committee of the Chilean Ministry of Health. Age as risk factor for death from pandemic (H1N1) 2009, Chile. Emerg Infect Dis 2011; 17: 1256-8.

11.- TORRES J P, O'RYAN M, HERVE B, ESPINOZA R, ACUÑA G, MAÑALICH J, et al. Impact of the novel influenza A (H1N1) during the 2009 autumn-winter season in a large hospital setting in Santiago, Chile. Clin Infect Dis 2010; 50: 860-8.

12.- WORLD HEALTH ORGANIZATION. Global Influenza Program-Surveillance and monitoring. http://www. who.int/influenza/en/ Consultado el 4 de marzo de 2013.

13.- CENTERS FOR DISEASE CONTROL AND PREVENTION. Seasonal Influenza. 2012-2013 Flu Season. http://www.cdc.gov/flu/about/season/index.htm Consultado el 4 de Marzo de 2013.

14.- MINISTERIO DE SALUD, CHILE. Departamento de Epidemiología. Vigilancia Epidemiológica. Informe Situación Epidemiológica de Influenza. http://www.deis. cl/estadisticas-mortalidad/ Consultado el 4 de marzo de 2013.

15.- BOIVIN G, HARDY I, TELLIER G, MAZIADE J. Predicting influenza infections during epidemics with use of a clinical case definition. Clin Infect Dis 2000; 31: 1166-9.

16.- MONTO AS, GRAVENSTEIN S, ELLIOTT M, COLOPY M, SCHWEINLE J. Clinical signs and symptoms predicting influenza infection. Arch Intern Med 2000; 160: 3243-7.

17.- CALL S A, VOLLENWEIDER M A, HORNUNG C A, SIMEL D L, MCKINNEY W P. Does this patient have 
influenza? JAMA 2005; 293: 987-97.

18.- ROJO JC, RUIZ-CONTRERAS J, FERNÁNDEZ M B, MARÍN M A, FOLGUEIRA L. Influenza-related hospitalizations in children younger than three years of age. Pediatr Infect Dis J 2006; 25: 596-601.

19.- WANG Y H, HUANG Y C, CHANG L Y, KAO H T, LIN P Y, HUANG C G, et al. Clinical characteristics of children with influenza A virus infection requiring hospitalization. J Microbiol Immunol Infect 2003; 36: 111-6.

20.- GOVAERT T M, DINANT G J, ARETZ K, KNOTTNERUS J A. The predictive value of influenza symptomatology in elderly people. Fam Pract 1998; 15: 16-22.

21.- WALSH E E, COX C, FALSEY A R. Clinical features of influenza A virus infection in older hospitalized persons. J Am Geriatr Soc 2002; 50: 1498-503.

22.- BABCOCK H M, MERZ L R, FRASER V J. Is influenza an influenza-like illness? Clinical presentation of influenza in hospitalized patients. Infect Control Hosp Epidemiol 2006; 27: 266-70.

23.- MILLER E K, GRIFFIN M R, EDWARDS K M, WEINBERG G A, SZILAGYI P G, STAAT M A, et al. Influenza burden for children with asthma. Pediatrics 2008; 121: 1-8.

24.- VARKEY J B, VARKEY B. Viral infections in patients with chronic obstructive pulmonary disease. Curr Opin Pulm Med 2008; 14: 89-94.

25.- CHARTRAND C, LEEFLANG M M, MINION J, BREWER T, PAI M. Accuracy of rapid influenza diagnostic tests. A meta-analysis. Ann Intern Med 2012; 156: $500-11$.

26.- JEFFERSON T, DEL MAR C B, DOOLEY L, FERRONI E, AL-ANSARY L A, BAWAZEER G A, et al. Physical interventions to interrupt or reduce the spread of respiratory viruses. Cochrane Database Syst Rev 2011; (7): CD006207.

27.- JEFFERSON T, JONES M A, DOSHI P, DEL MAR C B, HENEGHAN C J, HAMA R, et al. Neuraminidase inhibitors for preventing and treating influenza in healthy adults and children. Cochrane Database Syst Rev 2012; 1: CD008965.

28.- EBELL M H, CALL M, SHINHOLSER J. Effectiveness of oseltamivir in adults: a meta-analysis of published and unpublished clinical trials. Fam Pract 2012; 30: 125-33.

29.- WANG K, SHUN-SHIN M, GILL P, PERERA R, HARNDEN A. Neuraminidase inhibitors for preventing and treating influenza in children. Cochrane Database Syst Rev 2012; 1: CD002744.

30.- ASSOCIATION OF MEDICAL MICROBIOLOGY AND INFECTIOUS DISEASE CANADA. The use of antiviral drugs for Influenza: Guidance for Practitioners, 2012-2013. http://www.ammi.ca/ Consultado el 4 de marzo de 2013.

31.- THORLUND K, AWAD T, BOIVIN G, THABANE L. Systematic review of influenza resistance to the neuraminidase inhibitors. BMC Infect Dis 2011; 11: 134.

32.- ASTRAHAN P, ARKIN I T. Resistance characteristics of influenza to amino-adamantyls. Biochim Biophys Acta 2011; 1808: 547-53.

33.- CANTU J, TITA A T. Management of influenza in pregnancy. Am J Perinatol 2013; 30: 99-104.

34.- YUDIN M H. Optimizing knowledge of antiviral medications for prophylaxis and treatment of influenza during pregnancy. Expert Rev Respir Med 2011; 5: 495-501.

35.- MONTO A S, ROBINSON D P, HERLOCHER M L, HINSON J M JR, ELLIOTT M J, CRISP A. Zanamivir in the prevention of influenza among healthy adults: a randomized controlled trial. JAMA 1999; 282: 31-5.

36.- HAYDEN F G, ATMAR R L, SCHILLING M, JOHNSON C, PORETZ D, PAAR D, et al. Use of the selective oral neuraminidase inhibitor oseltamivir to prevent influenza. N Engl J Med 1999; 341: 1336-43.

37.- HAYDEN F G, GUBAREVA L V, MONTO A S, KLEIN T C, ELLIOT M J, HAMMOND J M, et al. Inhaled zanamivir for the prevention of influenza in families. Zanamivir Family Study Group. N Engl J Med 2000; 343: 1282-9.

38.- WELLIVER R, MONTO A S, CAREWICZ O, SCHATTEMAN E, HASSMAN M, HEDRICK J, et al. Effectiveness of oseltamivir in preventing influenza in household contacts: a randomized controlled trial. JAMA 2001; 285: 748-54.

39.- MONTO A S, PICHICHERO M E, BLANCKENBERG S J, RUUSKANEN O, COOPER C, FLEMING D M, et al. Zanamivir prophylaxis: an effective strategy for the prevention of influenza types A and B within households. J Infect Dis 2002; 186: 1582-8.

40.- BOWLES S K, LEE W, SIMOR A E, VEARNCOMBE M, LOEB M, TAMBLYN S, et al; Oseltamivir Compassionate Use Program Group. Use of oseltamivir during influenza outbreaks in Ontario nursing homes, 19992000. J Am Geriatr Soc 2002; 50: 608-16.

Correspondencia a:

Dr. Fernando Saldías Peñafiel

Departamento de Enfermedades Respiratorias

Pontificia Universidad Católica de Chile.

Teléfonos: (562) 26331541 - (562) 23543242

Fax: (562) 26335255

E-mail: fsaldias@med.puc.cl 